MARINE MAMMAL SCIENCE, 31(1): 106-121 (January 2015)

(C) 2014 Society for Marine Mammalogy

DOI: $10.1111 / \mathrm{mms} .12137$

\title{
Survival and abundance of short-finned pilot whales in the archipelago of Madeira, NE Atlantic
}

Filipe Alves ${ }^{1}$ and Ana Dinis, Madeira Whale Museum, 9200-031 Caniçal, Madeira, Portugal and University of Madeira, Centre of Life Sciences, Marine Biology Station of Funchal, 9000-107 Madeira, Portugal and CIIMAR/CIMAR, Interdisciplinary Centre of Marine and Environmental Research, University of Porto, 4050-123, Portugal; Cátia Nicolau, Madeira Whale Museum, 9200-031 Caniçal, Madeira, Portugal; Cláudia Ribeiro, Madeira Whale Museum, 9200-031 Caniçal, Madeira, Portugal and CIIMAR/CIMAR, Interdisciplinary Centre of Marine and Environmental Research, University of Porto, 4050-123, Portugal; Manfred Kaufmann, University of Madeira, Centre of Life Sciences, Marine Biology Station of Funchal, 9000-107 Madeira, Portugal and CIIMAR/CIMAR, Interdisciplinary Centre of Marine and Environmental Research, University of Porto, 4050-123, Portugal; CaterinA FortunA, Italian National Institute for Environmental Protection and Research, via Vitaliano Brancati 60, I 00144 Rome, Italy; Luís Freitas, Madeira Whale Museum, 9200-031 Caniçal, Madeira, Portugal and CIIMAR/CIMAR, Interdisciplinary Centre of Marine and Environmental Research, University of Porto, 4050-123, Portugal.

\begin{abstract}
Estimates of population parameters for the short-finned pilot whale, Globicephala macrorbynchus, are scarce in literature, contributing to an International Union for Conservation of Nature (IUCN) status of Data Deficient. In this study, photo-identification data collected over $7 \mathrm{yr}$ from Madeira were used to estimate for the first time survivorship, capture probability, and abundance in this species using mark-recapture methodology. The Cormack-Jolly-Seber model estimated that the adult islandassociated (i.e., resident and regular visitor) whales had a constant survival rate of 0.960 (95\% CI: $0.853-0.990$ ) and an annual capture probability varying between 0.372 (CI: $0.178-0.619$ ) and 0.843 (CI: 0.619-0.947). A parameterization of the Jolly-Seber model estimated that 140 island-associated whales (CI: 131-151) used the area throughout the course of the study. Based on a closed population model, the most precise (lower CV) annual estimate of the total number of pilot whales using the southern and eastern waters of Madeira $\left(\sim 900 \mathrm{~km}^{2}\right)$ in a 3 mo period covering summer/autumn was 334 animals (CI: 260-437). No trend was observed. Despite including biases, the approach used in this study provided plausible estimates of population parameters, which can contribute to the regional conservation strategies.
\end{abstract}

Key words: Globicephala macrorbynchus, heterogeneity, island-associated, mark-recapture, photo-identification, population models, population parameters, transience.

Population parameters are essential for health assessments and management decisions on a stock (Tyne et al. 2014). Little is known about the population parameters

${ }^{1}$ Corresponding author (e-mail: filipealves@museudabaleia.org or filipe.alves@ciimarmadeira.org). 
of the short-finned pilot whale, Globicephala macrorbynchus, which has a wide distribution from tropical to warm temperate waters (Olson 2009). The literature available describes estimates of mortality, growth, and reproductive rates from stranded and hunted whales in Japan (Kasuya and Marsh 1984), and reports estimates of abundance from line-transects (reviewed by Olson 2009). On a global scale, the conservation status of the short-finned pilot whale is described as Data Deficient and its population trend is unknown (IUCN 2012).

This is the first study presenting estimates of survival and abundance for shortfinned pilot whales using a noninvasive mark-recapture methodology based on photo-identification of naturally marked animals (Seber 1982, Hammond et al. 1990). Mark-recapture models have been applied to estimate population parameters in several taxa (e.g., Péron et al. 2013) including cetaceans (e.g., Speakman et al. 2010, Cantor et al. 2012). The reliability of estimates depends on the underlying assumptions of the model used, and these are not always easy to fulfill (Hammond 1986). To minimize bias in the present study, the model assumptions were carefully addressed according to each estimated parameter.

A photo-identification study of short-finned pilot whales in the archipelago of Madeira, Portugal, suggests varying patterns of occurrence with resident (up to 14 yr), transient, and regular visitor whales occupying the study area (Alves et al. 2013). In that study, several entire pods ( $72 \%$ of the 364 cataloged individuals) were captured only once during the study period (2003-2011), while other individuals were recaptured up to 33 times in multiple years. The transience and the emigration and re-immigration into the study area indicate wide ranging movement of these whales, causing unequal capture probabilities and consequently introducing problems for the analysis. It further demonstrates that the population under study uses a more extensive area than that surveyed.

Genetic analyses suggest that individuals of the different residency patterns encountered in Madeira may not be genetically isolated and that they may engage in mating (Alves et al. 2013). Additionally, the genetic information suggests that small groups are made up of related individuals with long-lasting relationships and that large groups are probably temporary associations of smaller groups. No other information related to stock boundaries or movements of short-finned pilot whales, from satellite tags or acoustics, is known to be available for the sampled population.

Estimating abundances of the island-associated whales, defined as residents or regular visitors (i.e., individuals with $>1$ capture, according to Alves et al. 2013) could be more relevant for addressing the impacts of localized disturbances (Conn et al. 2011). However, estimating the total number of animals that uses the area annually is also important for conservation management. Therefore, the aim of this study is to estimate population parameters of short-finned pilot whales in Madeira, namely, (1) survivorship, (2) abundance of the island-associated whales, and (3) abundance of all whales using the area (which includes transients).

\section{Material AND Methods}

\section{Data Collection}

Individual identification photographs were obtained through systematic boat surveys conducted around the islands of Madeira, Desertas, and Porto Santo $(\sim 4,500$ $\mathrm{km}^{2}$ ), and through nonsystematic and opportunistic surveys from a smaller area 
$\left(\sim 900 \mathrm{~km}^{2}\right)$ (Fig. 1). The systematic surveys followed predefined equal spaced zig-zag line-transects and were carried out from a research yacht. During the nonsystematic surveys an attempt was made to cover all distances and depths within the smaller area using a rigid inflatable boat (see details in Alves et al. 2013). The opportunistic surveys were carried out in tourist boats that operate bidaily trips to search for cetaceans, not pilot whales in particular, in the whole smaller selected area (Fig. 1). These opportunities allowed observers of our research team to collect additional digital photographs. All types of survey were performed year-round from 2003 to 2011, although only a subset was used in the analysis (see Data Set and Analysis). The survey effort varied according to the type of survey and among years, with a general increase in the number of surveys during the two latest years (Table 1).

Photographs of encountered short-finned pilot whales were made from a close distance, both on the left- and right-side, independently of age/sex class and dorsal fin distinctiveness. During all types of survey, sighting data included location, time of encounter, best estimate of group size and composition. While Nikon D2H cameras and lenses were used during the entire study period, Nikon D700 cameras were used only during 2010-2011. Time constraints limited full photographic coverage of some encounters during the systematic and opportunistic surveys.

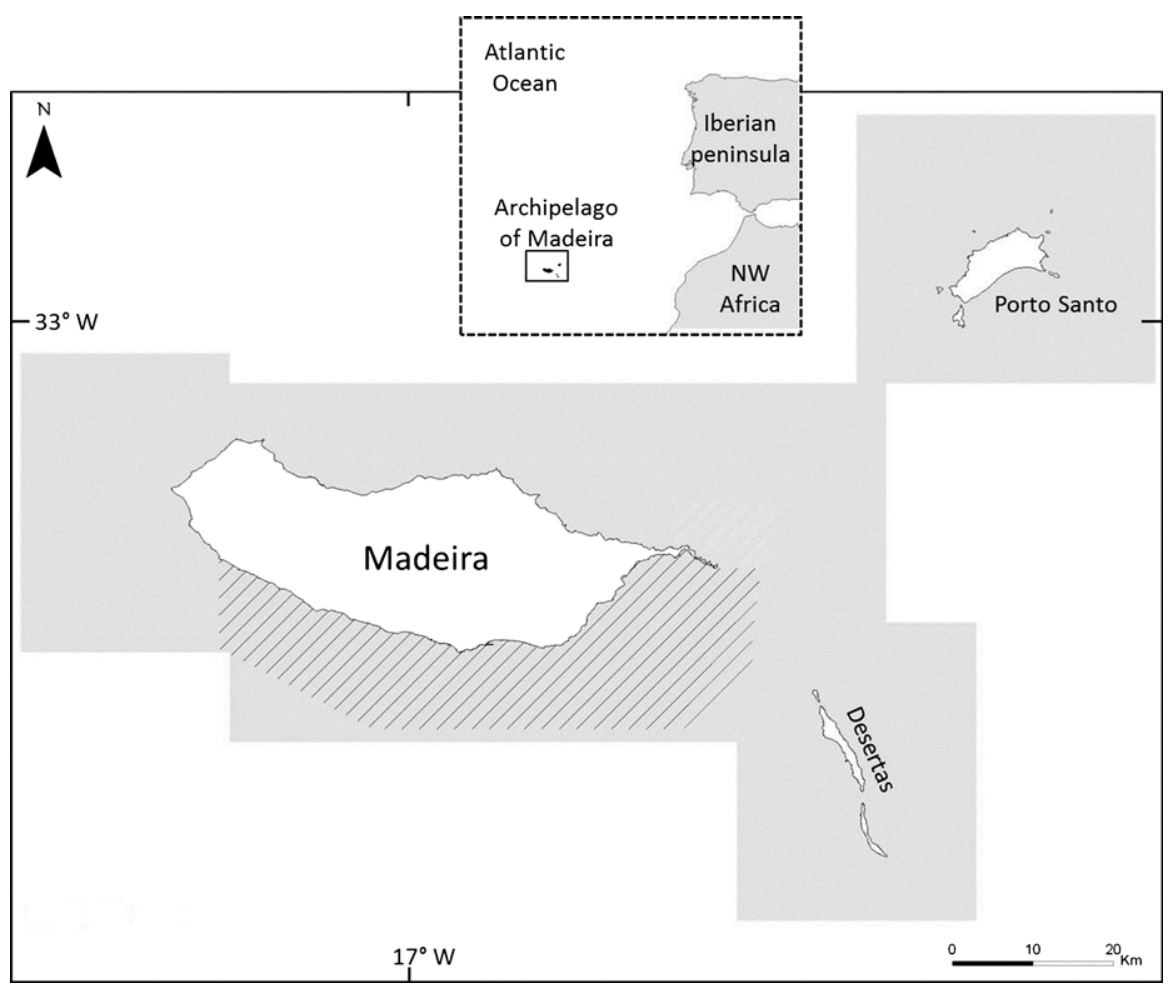

Figure 1. Surveyed area (in gray on the larger picture) in the archipelago of Madeira, Portugal, showing the smaller selected area used for the analysis of survival and abundances (in diagonal stripes). 
Table 1. Sampling effort and number of captures from photo-identification (of well-marked whales based on high-quality images) per period (start-end) used for the data analysis in this study. See text for details on each type of survey.

\begin{tabular}{cccccc}
\hline \hline & & \multicolumn{3}{c}{ Number of surveys/number of captures } \\
\cline { 3 - 6 } Year & \multicolumn{1}{c}{ Period } & Systematic & Nonsystematic & Opportunistic & Total \\
\hline 2005 & 28 July-22 October & 0 & $11 / 52$ & $7 / 8$ & $18 / 60$ \\
2006 & 19 July-27 September & 0 & $7 / 36$ & $6 / 1$ & $13 / 37$ \\
2007 & 25 July-19 October & $2 / 9$ & $7 / 27$ & $26 / 40$ & $35 / 76$ \\
2008 & 11 September-21 October & $1 / 12$ & 0 & $10 / 15$ & $11 / 27$ \\
2009 & 22 July-24 October & 0 & 0 & $11 / 46$ & $11 / 46$ \\
2010 & 26 July-28 October & $3 / 14$ & $8 / 35$ & $67 / 153$ & $78 / 202$ \\
2011 & 17 July-19 October & $2 / 8$ & $11 / 21$ & $81 / 131$ & $94 / 160$ \\
Total & & $8 / 43$ & $44 / 171$ & $208 / 394$ & $260 / 608$ \\
\hline
\end{tabular}

\section{Photo-identification}

A photo-identification catalog was compiled according to Würsig and Jefferson (1990) and photo processing and matching was done as described in Alves et al. (2013). Individuals were identified based only on unique notches on the trailing edge (Auger-Méthé and Whitehead 2007). A four-level photo quality was assigned to each photograph according to Friday et al. (2000) and a four-level independent distinctiveness category was given to each individual based on the number of notches in the dorsal fin. This study used only high-quality (HQ) images and well-marked (WM) whales. Photographs of HQ-images and WM-whales, as well as the definition of subadults and immatures are given in Alves et al. (2013).

\section{Data Set and Analysis}

Only data collected in the smaller selected area (Fig. 1) were used in the analysis as this area was more intensively researched and preferred by the whales (Alves 2013). Moreover, in order to minimize violation of model assumptions (see Discussion), data were restricted to 3 mo periods with more captures (summers/autumns) during 2005-2011 (Table 1). Analysis limited to data from a single survey type was less robust, with lower number of captures, lower precision, and higher overdispersion, than when using data from the three types of survey (Table S1). Therefore, every analysis in this study used the combined data from all types. Different approaches were used to estimate survival of adult whales $\left(\varphi_{\mathrm{ad}}\right)$, abundance of island-associated whales of all ages $\left(N_{\text {asso }}\right)$ and abundance of all whales using the area in each year $\left(N_{\text {tot }}\right)$. A summary of the data sets, models, and programs used is provided in Table 2.

The Cormack-Jolly-Seber (CJS) model (Cormack 1964, Jolly 1965, Seber 1965), which is based on the sighting histories of known individuals, was used to estimate survival $(\varphi)$ between years and capture probability $(p)$ for each year (Lebreton et al. 1992). Since mortality in mammals can vary according to age class (Reilly 1984, Gabriele et al. 2001, Silva et al. 2009), survival estimate was restricted to adults as this is the most representative category. Since recent findings discouraged distinguishing sex in pilot whales based on photographs (Augusto et al. 2013), the sex of animals was not taken into account. Moreover, survivorship was restricted to 
Table 2. Summary of the models used in this study.

\begin{tabular}{ccccccc}
\hline \hline ID & To estimate & Target whales & Period & $\begin{array}{c}\text { Population } \\
\text { model }\end{array}$ & $\begin{array}{c}\text { Model/ } \\
\text { estimator }\end{array}$ & Software \\
\hline$\varphi_{\text {ad }}$ & Survival & $\begin{array}{c}\text { Island-associated } \\
\text { adults }\end{array}$ & All years & Open & CJS & MARK \\
$N_{\text {asso }}$ & Abundance & $\begin{array}{c}\text { Island-associated } \\
\text { all-age }\end{array}$ & All years & Open & JS & POPAN \\
$N_{\text {tot }}$ & Abundance & All & Each year & Closed & Chao & CAPTURE \\
\hline
\end{tabular}

${ }^{\mathrm{a} S e e ~ M a t e r i a l ~ a n d ~ M e t h o d s ~ f o r ~ M o d e l / e s t i m a t o r ~ s p e c i f i c a t i o n s . ~}$

island-associated whales since the inclusion of transients and temporary emigrants, as in the case of this study (Alves et al. 2013), would violate the assumption of equal probability of capture (Cubaynes et al. 2010, Madon et al. 2013), resulting in a lower survival rate estimate. An ad hoc method presented by Pradel et al. (1997) was chosen to overcome the transience problem, excluding the first capture of each individual (e.g., Ramp et al. 2006). The ad hoc method was applied to all captured whales, resulting in the island-associated whales. This left truncation of the data set suppresses the influence of the lower survival estimate of individuals with null recapture probability, which corresponded to individuals captured only once, i.e., permanent emigration (Pradel et al. 1997). For this analysis, captures of individual whales made during the same year were pooled and each year was treated as a sampling occasion (Table 3). The left truncation and the exclusion of nonadults reduced the data set to 60 whales.

A parameterization of the Jolly-Seber model (Schwarz and Arnason 1996) was used to obtain an estimate of the number of island-associated whales that used the area throughout the course of the study. Here, whales of all ages could be estimated since the total abundance was based on the ratio between marked and unmarked animals (see Total Abundance). As in the previous open population model, the data set to estimate $N_{\text {asso }}$ was left truncated (e.g., Conn et al. 2011), captures of individual whales made during the same year were pooled and each year was treated as a sampling occasion (Table 3). The left truncation reduced the data set to 64 whales of all ages and sexes. Although the model used to estimate $N_{\text {asso }}$ could provide a survival estimate, this was not considered due to the inclusion of nonadult whales in this data set.

Table 3. Summary of the pooled data per period (see Table 1) in each year, with number of all photo-identified well-marked whales (of all age classes and before left truncation).

\begin{tabular}{cccc}
\hline \hline Year & Marked & New & In catalog \\
\hline 2005 & 47 & 47 & 47 \\
2006 & 29 & 20 & 67 \\
2007 & 46 & 25 & 92 \\
2008 & 24 & 7 & 99 \\
2009 & 34 & 16 & 115 \\
2010 & 84 & 39 & 154 \\
2011 & 58 & 17 & 171 \\
\hline
\end{tabular}

Note: The table summarizes the data used to estimate survival (before left truncating and excluding nonadults), abundance of island-associate whales (before left truncating), and abundance of all whales from Chapman's. 
Given that unequal capture probabilities between individuals are difficult to model in the open population framework, closed population models were chosen to estimate abundance of all whales using the area in each year since these can handle such type of heterogeneity (Chao 1989). To model each year independently in the software program CAPTURE, each 3 mo period contained multiple sampling occasions (between three and nine, Table 4), each comprising pooled data from close surveys (median $=$ $1 \mathrm{~d}$ apart, range: $0-5 \mathrm{~d}$ ) and separated by large intervals (median $=11 \mathrm{~d}$ apart, range: 5-52 d) according to Conn et al. (2011).

To estimate abundance of all whales an additional procedure was used in order to assess consistency. The Chapman's modification of the Petersen estimator (Hammond 2009) estimated abundance between every 2 yr using pooled data of individuals captured per three month period (Table 3). The data sets used to estimate $N_{\text {tot }}$ (either with CAPTURE or with the Chapman's) included all whales (i.e., of all age classes and not left truncated).

\section{Modeling $\varphi_{a d}$}

A goodness-of-fit (GOF) test was used to check if the chosen general model fitted the data adequately, using the program U-CARE (Choquet et al. 2009). GOF tests provided overall test statistics and four different tests, based on the comparison of observed vs. expected frequencies. In each test different aspects of the data were considered to evaluate potential violations of assumptions (Burnham et al. 1987, Choquet et al. 2009). The clearest tests are the TEST 2.CT, which is known to examine heterogeneity in capture probability and the TEST 3.SR, which is known to examine whether there is a transience effect (Choquet et al. 2005). The GOF test failed to reject the general model $(P=0.22)$ with only one of the components being slightly significant (TEST 3.SR, $P=0.04$ ) (Table S2). Furthermore, overdispersion is an important aspect to consider in mark-recapture data (Anderson et al. 1994). An estimation of the overdispersion factor (Lebreton et al. 1992), also called variance inflation factor $(\hat{c})$, was obtained by dividing the $\chi^{2}$ statistics of GOF tests by the number of degrees of freedom (Choquet et al. 2009). Whereas $1<\hat{c}<3$ is indicative of overdispersion in the data, a $\hat{c}>3$ may represent more fundamental problems (Lebreton et al. 1992). Given that the GOF test showed that model structures were correct and that the $\hat{c}$ was 1.298 we proceeded with the analysis.

Table 4. Number of sampling occasions, captures, and individuals marked per period (see Table 1) in each year, used to estimate abundances in program CAPTURE (see Table 2).

\begin{tabular}{cccc}
\hline \hline Year & Sampling occasions & Captures & Individuals marked \\
\hline 2005 & 4 & 57 & 47 \\
2006 & 4 & 36 & 28 \\
2007 & 6 & 66 & 40 \\
2008 & 3 & 21 & 21 \\
2009 & 5 & 37 & 32 \\
2010 & 9 & 151 & 78 \\
2011 & 8 & 105 & 53 \\
\hline
\end{tabular}

Note: Some individual captures fell in the intervals between the defined sampling occasions within years and were thus excluded from this analysis. As a consequence, in most years the number of individuals per year is less than given in the Marked column in Table 3. 
Two candidate models were used to estimate survival and capture probabilities. One included a more parameterized general model considering the full time-variation $(t)$, and the other considered constant (.) survival rates. The estimated $\hat{c}$ was incorporated in the model, allowing the overdispersion to be included in the computation of the standard error (SE) and confidence interval (CI, 95\%) of the parameter estimates $\varphi$ and $p$. For model selection, instead of the Akaike Information Criterion $\left(\mathrm{AIC}_{\mathrm{c}}\right)$, the Quasi-likelihood $\mathrm{AIC}_{\mathrm{c}}\left(\mathrm{QAIC}_{\mathrm{c}}\right)$ was used given that models were adjusted for overdispersion (Anderson et al. 1994). Model selection was based on the lowest $\mathrm{QAIC}_{c}$ value, and the strength of evidence of a specific model was measured using the normalized $\mathrm{QAIC}_{\mathrm{c}}$ weights.

\section{Modeling $\mathrm{N}_{\text {asso }}$}

Given that the data set used to estimate $N_{\text {asso }}$ had only four more (nonadult) whales than the data set used to estimate $\varphi_{\mathrm{ad}}$, and that only a fraction (the proportion of marked animals) of the total estimate of $N_{\text {asso }}$ would be tested, GOF tests were not applied. Two candidate models were used, one considering full time-variation $(t)$ and another considering constant (.) survival rates. The link functions were specified according to Cooch and White (2008). Model selection was based on the lowest $\mathrm{AIC}_{\mathrm{c}}$ value. The "Deviance" could not be directly computed (Cooch and White 2008).

\section{Modeling $\mathrm{N}_{t o t}$}

For the closed population models, model selection procedure for each year was performed from the "Appropriate" option that uses maximum value criteria. Yet, behavioral response to "capture" was not considered given that it is generally agreed that photo-identification of cetaceans should not lead to changes in capture probabilities (Wilson et al. 1999, Fortuna 2006). Therefore, heterogeneity in capture probabilities was taken into account in models considering the temporal variability $(t)$ and the individual heterogeneity $(b)$, as well as their combination $(t h)$ and the null model $(o)$. Moreover, estimates were restricted to the Chao estimator (Chao 1989) given it is suggested to be less biased than others (Brittain and Böhning 2009) and is likely more appropriate when sampling effort is not equal on each sampling occasion (as in this case) or when probabilities of capture are small (Fortuna 2006). Given that there is no GOF test available for closed population models, these were not adjusted for overdispersion.

Heterogeneity was also modeled with mixture models (Pledger 2000) using two mixtures of capture probabilities but these were discarded due to causing over-parameterization (not shown). Additionally, we attempted to address emigration with the Pollock's robust design (Pollock 1982; Kendall et al. 1995, 1997) but with no success due to requiring a larger number of captures (not shown). All mark-recapture modeling procedures were run in MARK (White and Burnham 1999). Trends were assessed through linear regressions using the R 2.14.2 statistical package (R Development Core Team 2012).

\section{Total abundance}

Given that estimates of abundance $(\hat{N})$ from models do not pertain to the whole population, total pilot whale abundance $\left(\hat{N}_{T}\right)$ occurring in the study area was 
calculated by dividing $\hat{N}$ by the mean proportion of WM-individuals $(\hat{\theta})$. This proportion was estimated as the number of WM-individuals divided by the number of all photographed individuals, using HQ-images from 32 groups of various sizes (333 individuals) where all individuals were captured (total $=348$ individuals). This was estimated for each year since a binomial GLM of the proportion of WM-individuals per year showed that most years were significant $(P<0.05)$. The variance of $\hat{N}_{T}$ was estimated using the delta method as $\hat{N}_{T}^{2} \times\left[\left(\operatorname{var} \hat{N} / \hat{N}^{2}\right)+\left(\operatorname{var} \hat{\theta} / \hat{\theta}^{2}\right)\right]$ (Urian et al., in press). Lower and upper log-normal CIs for $\hat{N}_{T}$ were calculated as MNA $\left.+\left(\hat{N}_{T}-\mathrm{MNA}\right) / C_{\mathcal{f}}\right)$, respectively, where MNA is the minimum number of animals known to be alive in the population (i.e., the number of animals that were captured) and $C_{\int}=\exp \left\{1.96 \sqrt{\ln \left[1+\operatorname{var} \hat{N}_{T} /\left(\hat{N}_{T}-\mathrm{MNA}\right)^{2}\right]}\right\}$ (Thompson et al. 1998).

\section{Model Assumptions}

Assumptions of open population models include: (1) marks are not lost or missed, (2) individuals are immediately released after being sampled, and the duration of each sampling event is small in relation to the total duration of the sampling period, (3) all marked individuals in the population that are alive on a given sampling occasion have the same probability of surviving to the next sampling occasion, (4) all animals have the same capture probability, (5) captures are assumed independent of one another, (6) all emigration is permanent, and (7) marking does not affect catchability (Hammond 1986, Hammond et al. 1990, Kendall et al. 1995).

Closed models require the additional assumption that the population is closed to births, deaths, and permanent immigration and emigration (Hammond 1986, 2009). Potential violations of model assumptions are addressed in the Discussion.

\section{RESULTS}

\section{Estimates of $\varphi_{a d}$}

The full time-variation model fitted the data poorly, and the model with constant survival represented the best model (Table S3). After applying the $\hat{c}$, the estimated constant survival rate was 0.960 ( $\mathrm{SE}=0.028$, 95\% CI: 0.853-0.990). Capture probabilities from the best model fluctuated between 0.372 ( $\mathrm{SE}=0.120$, CI: 0.178-0.619) in 2008 and 0.843 ( $\mathrm{SE}=0.081$, CI: 0.619-0.947) in 2010 (Fig. 2). A linear regression fitted to the capture probabilities showed no significant trend (adjusted $r^{2}=$ $-0.04, P=0.43)$.

\section{Estimates of $\mathrm{N}_{\text {asso }}$}

The model with constant survival represented the best model (Table S4). The estimated number of marked island-associated whales using the selected area throughout the course of the study was 69 animals (CV $=0.05$, CI: 66-80). Correcting for the unmarked proportion of the population $(51 \%)$ the total $N_{\text {asso }}$ was estimated at 140 animals (CI: 131-151). 
Estimates of $\mathrm{N}_{\text {tot }}$

After correcting for the proportion of unmarked whales, total abundance estimates varied from a low of 105 whales (CI: 83-136) in 2006 according to $M(0)$ to a high of 334 (CI: 260-437) in 2010 according to $M(t)$ (Table 5). Parameters for 2008 could not be estimated. A linear regression fitted to the abundances showed no significant trend (adjusted $r^{2}=0.33, P=0.14$ ).

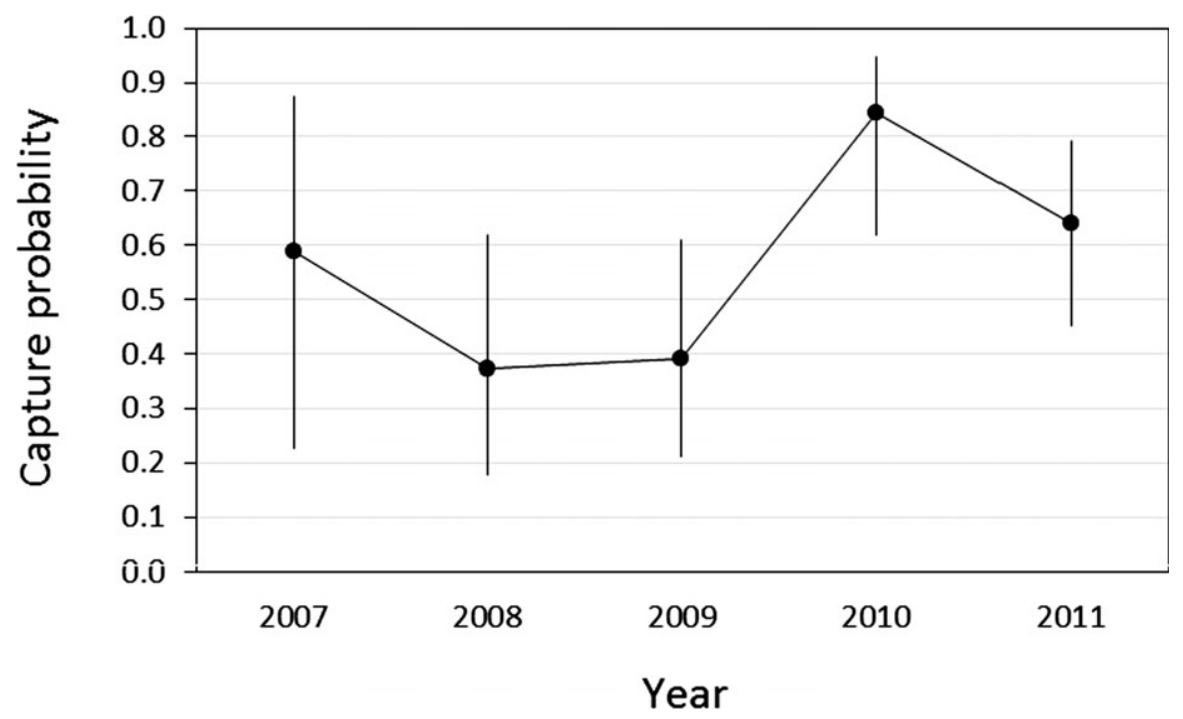

Figure 2. Estimates of capture probability for island-associated adult whales with $95 \% \mathrm{CI}$ (vertical bars).

Table 5. Estimates of the proportion of well-marked individuals $(\theta)$ and abundance $(N)$ from the closed population models that were used to estimate total abundance $\left(N_{\text {tot }}\right)$ of whales using the selected area (see Fig. 1) per period (see Table 1) in each year.

\begin{tabular}{|c|c|c|c|c|c|c|c|c|}
\hline \multirow[b]{2}{*}{ Year } & \multirow[b]{2}{*}{$\theta$} & \multirow[b]{2}{*}{ SE } & \multirow[b]{2}{*}{$n$} & \multicolumn{3}{|c|}{ Model } & \multicolumn{2}{|c|}{ Total } \\
\hline & & & & Selected & $N$ & $\mathrm{CV}$ & $N_{\text {tot }}$ & $95 \% \mathrm{CI}$ \\
\hline 2005 & 0.80 & 0.07 & 30 & $M(t)$ & 115 & 0.31 & 144 & 109-198 \\
\hline 2006 & $0.49^{a}$ & 0.10 & 0 & $M(o)$ & 52 & 0.26 & 105 & $83-136$ \\
\hline 2007 & 0.52 & 0.08 & 27 & $M(t h)$ & 93 & 0.26 & 179 & $134-247$ \\
\hline 2008 & 0.57 & 0.09 & 44 & - & - & - & - & - \\
\hline 2009 & 0.63 & 0.08 & 27 & $M(o)$ & 98 & 0.38 & 156 & $109-231$ \\
\hline 2010 & 0.37 & 0.04 & 35 & $M(t)$ & 124 & 0.16 & 334 & $260-437$ \\
\hline 2011 & 0.43 & 0.03 & 185 & $M(b)$ & 91 & 0.20 & 213 & $174-265$ \\
\hline
\end{tabular}

Note: Appropriate model given in CAPTURE was used for model selection, and Chao was used as estimator (see Material and Methods). See text for definition of $M(t), M(b), M(t h)$ and $M$ $(0)$.

${ }^{a}$ Given there were no completely captured groups in $2006(n=0)$, the overall mean was used for that year. 
Estimates from the Chapman's modification are shown only for the pair of years 2010-2011 as this was considered the most reliable and representative one, because of the higher sampling effort in those periods. As a result, this pair of years presented the lowest $\mathrm{CV}$ and used the largest number of captures. The estimated number of marked whales was 142 animals $(\mathrm{CV}=0.08)$. Correcting for the unmarked proportion of the population for those years $(58 \%)$ the total number of all whales using the selected area in 2010 and 2011 was 340 animals (CI: 306-381).

\section{DisCUSSION}

\section{Model Assumptions}

A major contribution to avoid violation of the first two assumptions (that marks are not lost or missed, and that the duration of each sampling event is small) was made by (1) using only WM-individuals and HQ-images, (2) taking into account that those whales have a low rate of mark change in the dorsal fin (every 6.6-8.0 yr, Alves et al. 2013), and (3) collecting captures from short-term photo-identification events (Wilson et al. 1999, Stevick et al. 2001).

The third and fourth assumptions (that all animals have equal survival and capture probability) can be easily violated when using heterogeneous data as in this case. Equal capture probability is more likely to be achieved if animals mix between sampling periods. The observation that a group of pilot whales traveled $\sim 600 \mathrm{~km}$ between Madeira and the Canary Islands in $20 \mathrm{~d}$ (AS, FA, AD, LF and V M, unpublished data) suggests that mixing is likely to have occurred between sampling periods in the present study, especially if we consider that these were on average $11 \mathrm{~d}$ apart (range: 5-52 d) and that the study area was relatively small. However, the fact that a high percentage of new individuals was identified each year, including the last year of the study (see Table 3), and that about two thirds of the individuals were captured only once (see Fig. S1), strongly suggests temporary immigration into the study area and transiency. The high number of recaptures observed for a subset of the catalogued individuals and the low rate of mark change in the dorsal fin (Alves et al. 2013) corroborates that the continuous addition of new individuals cannot be explained by the acquisition of new marks. Therefore, the population is assumed to be open, leading to heterogeneous data. The first capture of each individual was censored to reduce transience, and this was addressed through GOF tests. Despite still indicating transience, the tests show that model structures are correct. Moreover, the $\hat{c}$-value indicates that the excess variation was within acceptable limits. Nonetheless, the assumption that all animals have the same capture probability can rarely be met in a real study (Evans and Hammond 2004).

The assumption that captures are assumed independent of one another is likely to be violated in most studies estimating population parameters in cetaceans due to their social structure, and a gregarious species such as the short-finned pilot whale (Heimlich-Boran 1993) is no exception. Yet, to the best of our knowledge this issue has not been properly addressed in cetaceans' studies (Choquet et al. 2013). Although the population used in this study is socially structured, not all pairs of individuals are expected to have been seen closely associated the entire time (Alves et al. 2013). Moreover, by pooling different days into one session, which joined data of many different social groups, the violation of this assumption was greatly minimized. In all cases, this may have caused only an underestimation of the model-conditioned 
standard errors and did not lead to biased estimates (Williams et al. 2002, Conn et al. 2011).

While the assumption that marking does not affect the catchability of an animal is assumed to be met through the use of photo-identification in cetaceans (Hammond et al. 1990, Wilson et al. 1999), possible violations to the assumption of closure should not be discarded. Nevertheless, analyzing a data set restricted to a three month period likely contributed to ensure, or at least minimize the violation of, closure.

\section{Survival}

Excluding the first capture of each individual appears to be a useful approach to address the heterogeneity arising from transience. The same procedure was used in Ramp et al. (2006) to deal with transience in estimating survival rates of blue whales (Balaenoptera musculus). Yet, even after truncation, there was still heterogeneity in our data set. Since permanent emigration was no longer a problem, it is assumed that this heterogeneity was caused by the presence of temporary emigrant whales (Alves et al. 2013), which unfortunately could not be addressed with the Pollock's robust design. Additionally, incorporating a variance inflation factor increased the SE and the CI of the estimates but reflected the extra amount of variance in the data.

Silva et al. (2009) used CJS and robust design models to estimate survivorship, but only the former provided reliable results when dealing with transience, and Ramp et al. (2006) estimated survivorship using only open CJS models, as in the case of the present study. The best estimate presented here considers only the island-associated adult pilot whales. Nevertheless, the survival rate should not vary greatly among residency-type due to being a long-lived mammal species.

The analysis excluded nonadult individuals, which eliminated possible heterogeneity arising from differences in age class, but included whales of both sexes. Kasuya and Marsh (1984) described that in Japan male short-finned pilot whales have a higher mortality rate than females at any given age. As so, further photo-identification studies on this population should combine genetic sampling for sex determination in order to address this possible source of heterogeneity.

The high survival rate of 0.960 presented here is in accordance with estimates for other long-lived cetaceans (Barlow and Clapham 1997, Currey et al. 2009), and agrees with the mortality rates of $4.5 \%$ for females and $8.3 \%$ for males of this species (Kasuya and Marsh 1984; noting they considered all age classes). Nonetheless, the survival rate described here is lower than the estimate reported for adult long-finned pilot whales, G. melas, in the Strait of Gibraltar (0.982, CI: 0.955-0.993; Verborgh et al. 2009).

\section{Capture Probability}

Capture probabilities showed no trend but varied during the study period, suggesting time-dependency, as expected in the majority of mark-recapture studies in cetaceans (Hammond 2009). Although any annual fluctuation in whale abundance or environmental factors such as distribution and availability of prey might have contributed to variations in capture probabilities, most variations could likely be explained by differences in sampling effort. This could include differences in the survey effort, type of survey, type of vessels, or even type of cameras. 


\section{Abundance}

This study estimated that 140 island-associated whales (CI: 131-151) used the southern and eastern waters of Madeira during the three month periods covering summers/autumns of 2005-2011. Based on individuals captured on $\geq 4$ encounters with high coverage during all year, Alves et al. (2013) described at least eight pods of resident and regular visitor pilot whales in Madeira, each with an estimated mean of 15 individuals ( $\mathrm{SD}=9$, range: $4-29)$. The number of island-associated whales based on pods is likely to include others than those $\sim 120$ animals ( 8 pods of 15 individuals) if accounting for the individuals captured on $<4$ occasions. Therefore, and not discounting potential bias due to heterogeneity of capture probability, this corroborates that the estimated number of island-associated whales found in this study may be representative of the animals using the area throughout the year.

On the other hand, total abundances are difficult to model with open population models due to the presence of transients that induces unequal capture probabilities (Hammond 1986). Instead, closed models were used, which allowed accounting for heterogeneity since robust estimators have been developed to obtain less biased population estimates (Otis et al. 1978, Chao 1989). In general, abundance estimates varied between years, although no significant trend was observed. The most precise estimate (based on the lower CV, e.g., Silva et al. 2009) corresponds to 2010, the year with greater sampling effort and higher estimate of abundance. Thus, the most precise estimate of short-finned pilot whales using the southern and eastern waters of Madeira in a 3 mo period covering summer/autumn is 334 animals (CI: 260-437). Although, it should be noted that the annual estimates can be overestimated since they do not incorporate temporary emigration (i.e., some animals may be available in some years but not in others). The Chapman's modification estimated that the total number of all whales using the same area during the period 2010-2011 was 340 animals (CI: 306-381). This estimate, that may include biases associated with the violation of closure between periods, suggests that the estimates obtained from Chao models may be overestimated.

The approximately 213 long-finned pilot whales reported every summer in the central part of the Strait of Gibraltar (Verborgh et al. 2009) are within the range of our annual estimates, notwithstanding that these studies covered different methodological approaches, species, and areas. No other estimates of abundance using markrecapture data on pilot whales are known to have been reported to date.

\section{Conclusions}

Analyzing free-ranging animals in an open pelagic environment induce limitations in the data set that consequently challenge the analysis. Yet, the approach used in this study provided plausible estimates for survival of adult whales (within the range of other long-lived cetacean species) as well as for abundance of island-associated whales and of individuals using the area seasonally. The estimates presented here should be taken in consideration by managers as a baseline for conservation strategies. The area used for the analyses coincides with the main area of marine traffic in the island of Madeira and with the main area of operation of whale-watching vessels. Similarly, the period of year used in the analyses covers the main season of that industry. Given that the whale-watching industry is increasing in Madeira, it can become a potential pressure to the island-associated pilot whales. Therefore, we stress the need for longterm monitoring, especially of the animals that use the area regularly, since it could 
help to assess the health of the population. As a future consideration, a larger data set covering a higher number of years would likely improve the issue of temporary emigration since it would increase the chances of recapturing those whales which visit the area sporadically.

\section{ACKNOWLEDGMENTS}

Dedicated to our friend Miguel Silva, the skipper of the research yacht used in the surveys, who died in December 2013 when trying to "save" the vessel during a storm in Madeira. Thanks to the crew members João Viveiros and Hugo Vieira for their dexterity that greatly facilitated sample collection; the whale-watching operators Carlos Silva, Rita Ferreira, Luís Dias, Raquel Marques, Claudia Gomes, and Rafael Gomes who greatly contributed with photographs; Ana Higueras, Marianne Böhm-Beck, and Jonatan Svensson for field work assistance; Adalberto Carvalho for assistance with the map; Município de Machico and EU programs for co-funding the projects CETACEOS-MADEIRA I and II (LIFE99 NAT/P/006432 and LIFE+ NAT/P/000646), and MACETUS and EMECETUS (FEDER/INTERREG III-B MAC/4.2/ M10 and 05/MAC/4.2/M10); Cláudia Faustino, Yves Verlinden, and Eva Van Meervenne for the revision of the manuscript; Renaud de Stephanis and Philippe Verborgh for statistical comments; and Daryl J. Boness, Philip Hammond, and three anonymous reviewers for valuable suggestions.

\section{LiterATURE Cited}

Alves, F. 2013. Population structure, habitat use and conservation of short-finned pilot whales (Globicephala macrorbynchus) in the archipelago of Madeira. Ph.D. thesis, University of Madeira, Funchal, Portugal. 186 pp.

Alves, F., S. Quérouil, A. Dinis, et al. 2013. Population structure of short-finned pilot whales in the oceanic archipelago of Madeira based on photo-identification and genetic analyses: Implications for conservation. Aquatic Conservation: Marine and Freshwater Ecosystems 23:758-776.

Anderson, D. R., K. P. Burnham and G. C. White. 1994. AIC model selection in overdispersed capture-recapture data. Ecology 75:1780-1793.

Auger-Méthé, M., and H. Whitehead. 2007. The use of natural markings in studies of longfinned pilot whale (Globicephala melas). Marine Mammal Science 23:77-93.

Augusto, J. F., T. R. Frasier and H. Whitehead. 2013. Using photography to determine sex in pilot whales (Globicephala melas) is not possible: Males and females have similar dorsal fins. Marine Mammal Science 29:213-220.

Barlow, J., and P. J. Clapham. 1997. A new birth-interval approach to estimating demographic parameters of humpback whales. Ecology 78:535-546.

Brittain, S., and D. Böhning. 2009. Estimators in capture-recapture studies with two sources. Advances in Statistical Analysis 93:23-47.

Burnham, K. P., D. R. Anderson, G. C. White, C. Brownie and K. H. Pollock. 1987. Design and analysis methods for fish survival experiments based on release-recapture. American Fisheries Society Monographs 5, Bethesda, MD.

Cantor, M., L. L. Wedekin, F. G. Daura-Jorge, M. R. Rossi-Santos and P. C. Simões-Lopes. 2012. Assessing population parameters and trends of Guiana dolphins (Sotalia guianensis): An eight-year mark-recapture study. Marine Mammal Science 28:63-83.

Chao, A. 1989. Estimating population size for sparse data in capture-recapture experiments. Biometrics 45:427-438.

Choquet, R., A. M. Reboulet, J. D. Lebreton, O. Gimenez and R. Pradel. 2005. U-CARE 2.2 (Utilities-CApture-REcapture) user's manual. CEFE, Montpellier, France. 
Choquet, R., J. D. Lebreton, O. Gimenez, A. M. Reboulet and R. Pradel. 2009. U-CARE: Utilities for performing goodness of fit tests and manipulating capture-recapture data. Ecography 32:1071-1074.

Choquet, R., A. Sanz-Aguilar, B. Doligez, E. Nogué, R. Pradel, L. Gustafsson and O. Gimenez. 2013. Estimating demographic parameters from capture-recapture data with dependence among individuals within clusters. Methods in Ecology and Evolution 4:474-482.

Conn, P. B., A. M. Gorgone, A. R. Jugovich, B. L. Byrd and L. J. Hansen. 2011. Accounting for transients when estimating abundance of bottlenose dolphins in Choctawhatchee Bay, Florida. Journal of Wildlife Management 75:569-579.

Cooch, E., and G. White. 2008. Program MARK: A gentle introduction, 7th edition. Colorado State University, Fort Collins CO.

Cormack, R. M. 1964. Estimates of survival from the sighting of marked animals. Biometrika 51:429-438.

Cubaynes, S., R. Pradel, R. Choquet, et al. 2010. Importance of accounting for detection heterogeneity when estimating abundance: The case of French wolves. Conservation Biology 24:621-626.

Currey, R. J. C., S. M. Dawson, E. Slooten, et al. 2009. Survival rates for a declining population of bottlenose dolphins in Doubtful Sound, New Zealand: An information theoretic approach to assessing the role of human impacts. Aquatic Conservation: Marine and Freshwater Ecosystems 19:658-670.

Evans, P. G. H., and P. S. Hammond. 2004. Monitoring cetaceans in European waters. Mammal Review 34:131-156.

Fortuna, C. M. 2006. Ecology and conservation of bottlenose dolphins (Tursiops truncatus) in the north-eastern Adriatic Sea. Ph.D. thesis, University of St. Andrews, St. Andrews, U.K. 256 pp.

Friday, N., T. D. Smith, P. T. Stevick and J. Allenin. 2000. Measurement of photographic quality and individual distinctiveness for the photographic identification of humpback whales, Megaptera novaeangliae. Marine Mammal Science 16:355-374.

Gabriele, C. M., J. M. Straley, S. A. Mizroch, et al. 2001. Estimating the mortality rate of humpback whale calves in the central North Pacific Ocean. Canadian Journal of Zoology 79:589-600.

Hammond, P. S. 1986. Estimating the size of naturally marked whale populations using capture-recapture techniques. Report to the International Whaling Commission (Special Issue 8):253-282.

Hammond, P. S. 2009. Mark-recapture. Pages 705-709 in W. F. Perrin, B. Würsig and J. G. M. Thewissen, eds. Encyclopedia of marine mammals, 2nd edition. Academic Press, Amsterdam, The Netherlands.

Hammond, P. S., S. A. Mizroch and G. P. Donovan, eds. 1990. Individual recognition of cetaceans: Use of photo-identification and other techniques to estimate population parameters. Report to the International Whaling Commission, (Special Issue 12).

Heimlich-Boran, J. R. 1993. Social organization of the short-finned pilot whale, Globicephala macrorbynchus, with special reference to the comparative social ecology of delphinids. Ph.D. thesis, Cambridge University, Cambridge, U.K. 134 pp.

IUCN. 2012. IUCN Red List of Threatened Species. Version 2012.1. Available at http:// www.iucn redlist.org.

Jolly, G. M. 1965. Explicit estimates from capture-recapture data with both death and immigration stochastic model. Biometrika 52:225-247.

Kasuya, T., and H. Marsh. 1984. Life history and reproductive biology of the short-finned pilot whale, Globicephala macrorbynchus, off the Pacific Coast Japan. Report to the International Whaling Commission (Special Issue 6):259-310.

Kendall, W. L., K. H. Pollock and C. Brownie. 1995. A likelihood-based approach to capturerecapture estimation of demographic parameters under the robust design. Biometrics 51:293-308. 
Kendall, W. L., J. D. Nichols and J. E. Hines. 1997. Estimating temporary emigration using capture-recapture data with Pollock's robust design. Ecology 78:563-578.

Lebreton, J. D., K. P. Burnham, J. Clobert and D. R. Anderson. 1992. Modelling survival and testing biological hypotheses using marked animals: A unified approach with case studies. Ecological Monographs 62:67-118.

Madon, B., C. Garrigue, R. Pradel and O. Gimenez. 2013. Transience in the humpback whale population of New Caledonia and implications for abundance estimation. Marine Mammal Science 29:669-678.

Olson, P. 2009. Pilot whales Globicephala melas and G. macrorbynchus. Pages 847-852 in W. F. Perrin, B. Würsig and J. G. M. Thewissen, eds. Encyclopedia of marine mammals, 2nd edition. Academic Press, Amsterdam, The Netherlands.

Otis, D. L., K. P. Burnham, G. C. White and D. R. Anderson. 1978. Statistical inference for capture data on closed animal populations. Wildlife Monographs 62:1-135.

Péron, G., Y. Ferrand, G. Leray and O. Gimenez. 2013. Waterbird demography as indicator of wetland health: The French-wintering common snipe population. Biological Conservation 164:123-128.

Pledger, S. 2000. Unified maximum likelihood estimates for closed capture-recapture models with heterogeneity. Biometrics 56:434-442.

Pollock, K. H. 1982. A capture-recapture design robust to unequal probability of capture. The Journal of Wildlife Management 46:757-760.

Pradel, R., J. E. Hines, J. D. Lebreton and J. D. Nichols. 1997. Capture-recapture survival models taking account of transients. Biometrics 53:60-72.

R Development Core Team. 2012. R: A language and environment for statistical computing. R Foundation for Statistical Computing, Vienna, Austria.

Ramp, C., M. Bérubé, W. Hagen and R. Sears. 2006. Survival of adult blue whales Balaenoptera musculus in the Gulf of St. Lawrence. Canada. Marine Ecology Progress Series 319:287-295.

Reilly, S. 1984. Observed and published rates of increase in gray whales, Eschrichtius robustus. Report to the International Whaling Commission (Special Issue 6):389-399.

Schwarz, C. J., and A. N. Arnason. 1996. A general methodology for the analysis of openmodel capture recapture experiments. Biometrics 52:860-873.

Seber, G. A. F. 1965. A note on the multiple recapture census. Biometrika 52:249-259.

Seber, G. A. F. 1982. The estimation of animal abundance and related parameters. 2nd edition. MacMillan, New York, NY.

Silva, M. A., S. Magalhães, R. Prieto, R. S. Santos and P. S. Hammond. 2009. Estimating survival and abundance in a bottlenose dolphin population taking into account transience and temporary emigration. Marine Ecology Progress Series 392:263-276.

Speakman, T. R., S. M. Lane, L. H. Schwacke, P. A. Fair and E. S. Zolman. 2010. Markrecapture estimates of seasonal abundance and survivorship for bottlenose dolphins (Tursiops truncatus) near Charleston, South Carolina, USA. Journal of Cetacean Research and Management 11:153-162.

Stevick, P. T., P. J. Palsbøll, T. D. Smith, M. V. Bravington and P. S. Hammond. 2001. Errors in identification using natural markings: Rates, sources, and effects on capturerecapture estimates of abundance. Canadian Journal of Fisheries and Aquatic Sciences 58:1861-1870.

Thompson, W. L., G. White and C. Gowan. 1998. Monitoring vertebrate populations. Academic Press, New York, NY.

Tyne, J. A., K. H. Pollock, D. W. Johnston and L. Bejder. 2014. Abundance and survival rates of the Hawai'i Island associated spinner dolphin (Stenella longirostris) stock. PLoS ONE 9(1):e86132.

Urian, K., A. J. Read and A. Gorgone, et al. In press. Recommendations for photoidentification methods used in capture-recapture models with cetaceans. Marine Mammal Science. 
Verborgh, P., R. de Stephanis, S. Pérez, Y. Jaget, C. Barbraud and C. Guinet. 2009. Survival rate, abundance, and residency of long-finned pilot whales in the Strait of Gibraltar. Marine Mammal Science 25:523-536.

White, G. C., and K. P. Burnham. 1999. Program MARK: Survival estimation from populations of marked animals. Bird Study (Supplement) 46:120-138.

Williams, B. K., J. D. Nichols and M. J. Conroy. 2002. Analysis and management of animal populations. Academic Press, San Diego, CA.

Wilson, B., P. S. Hammond and P. M. Thompson. 1999. Estimating size and assessing trends in a coastal bottlenose dolphin population. Ecological Applications 9:288-300.

Würsig, B., and T. A. Jefferson. 1990. Methods of photo-identification for small cetaceans. Report to the International Whaling Commission (Special Issue 12):43-52.

Received: 19 September 2013

Accepted: 17 March 2014

\section{SUPPORTING INFORMATION}

The following supporting information is available for this article online at http:// onlinelibrary.wiley.com/doi/10.1111/mms.12137/suppinfo.

Table S1. Estimated constant survival rate ( $\varphi$, using the CJS model), precision of the mean (SE and 95\% CI), and overdispersion factor ( $\hat{c}$, using GOF tests) for data sets from different type(s) of survey.

Table S2. Results from goodness-of-fit tests run in U-CARE for the data set used to estimate survival in the Cormack-Jolly-Seber model.

Table S3. Model selection for the survival (using Cormack-Jolly-Seber) candidate models of probabilities of survival $(\varphi)$ and capture $(p)$, considering constant (.) and time-variation ( $t)$; $\triangle$ QAICc reflects the QAICc difference from Model 1.

Table S4. Model selection for the abundance of island-associated whales (using Jolly-Seber) candidate models of probabilities of survival $(\varphi)$, capture $(p)$ and probability of entry (pent), considering constant (.) and time-variation $(t)$; $\triangle$ AICc reflects the AICc difference from Model 1.

Figure S1. Discovery curve for all and for island-associated (all excluding first capture) pilot whales, considering only well-marked individuals based on high-quality images for all studied years (separated by vertical bars) and area. 